\title{
CHARACTERIZATION OF LIGNIN PRECIPITATED FROM THE SODA BLACK LIQUOR OF OIL PALM EMPTY FRUIT BUNCH FIBERS BY VARIOUS MINERAL ACIDS
}

\author{
M.N. Mohamad Ibrahim*, S.B. Chuah \\ School of Chemical Sciences \\ Universiti Sains Malaysia, 11800 Minden, Pulau Pinang, Malaysia
}

\section{W.D. Wan Rosli}

School of Industrial Technology, Universiti Sains Malaysia, 11800 Minden, Pulau Pinang, Malaysia

Received 28 May 2003, Accepted 22 September 2003

\begin{abstract}
Soda lignin from oil palm empty fruit bunch was directly isolated by various mineral acids i.e. sulfuric acid, hydrochloric acid, phosphoric acid and nitric acid at three levels of concentration (20\% v/v, 60\% v/v and concentrated). A comparison study was performed through physicochemical properties and structural features using FT-IR, UV, ${ }^{13} \mathrm{C}-\mathrm{NMR}$ and nitrobenzene oxidation. The FT-IR results showed that there is no significant difference between the main structures of the lignin isolated by various acids. However, low concentration of phosphoric acid is preferable because of its highest yield. The S: V: H ratio of 7-15:6-11:1 as evaluated by the nitrobenzene oxidation procedure suggests that soda lignin can be classified as belonging to either the cereal straw on grass type. The UV results indicate that phosphoric acid consistently gave the highest absorbance value among the four acids tested in this study regardless of its concentration level. The $\mathrm{C}^{13}$-FTNMR spectra, suggest that the lignin structure is independent of the type of acid used for precipitation.
\end{abstract}

\section{INTRODUCTION}

Oil palm (Elaeis guineensis) is a native of West Africa. It was introduced to various parts of the tropics for its oil-producing fruit. In Malaysia, it is estimated that 2.28 million ha of land is being cultivated with oil palm trees ${ }^{1}$. Besides producing palm oil, the industry also generates massive amounts of lignocellulosic residues such as trunks, fronds and empty fruit bunches (EFB). Paper grade pulps from these fibres have since been established ${ }^{2,3,4}$. However the lignin extracted during

Corresponding author e-mail: mnm@usm.my 
the pulping process has so far not being investigated for its usefulness. Before its applications can be considered, knowledge of its structural characterization is required; this study presents such an effort.

Lignin is an amorphous polyphenolic material arising from an enzyme-mediated dehydrogenates polymerization of three major phenylpropanoid monomers, which are coniferyl, sinapyl and pcoumaryl alcohol ${ }^{5}$. The lignin structural elements are linked by carbon-carbon and ether bonds to form tri-dimensional network associated with the hemicelluloses polysaccharides inside the cell wal ${ }^{16}$. Lignin is usually insoluble in all solvents and can only be degraded by physical or chemical treatments ${ }^{7}$. During the chemical pulping process at high-temperature and high-pressure, degradation of lignin occurs and dissolves into the spent liquor. The delignification reactions involved the cleavage of non-phenolic $\beta$-O-4 linkage, phenolic $\alpha$-O-4 linkage and releasing from the associated by the polysaccharide ${ }^{8,9}$.

The structure of lignin obtained from the EFB fiber is more complex then the structure of lignin extracted from wood due to a complex arrangement of syringyl- and guaiacyl- propane units together with p-hydroxy-propane unit in the EFB fiber. The EFB fiber contains about 17.2\% lignin, which is relatively low compare to hardwood and softwood materials ${ }^{10}$.

The objective of this investigation is to gain a better understanding on the effects of different mineral acids used in recovering soda lignin. EFB lignin was isolated from the soda black liquor by various type of mineral acids i.e. sulfuric acid, hydrochloric acid, phosphoric acid and nitric acid at three levels of concentration (concentrated, $60 \% \mathrm{v} / \mathrm{v}$ and $20 \% \mathrm{v} / \mathrm{v}$ ). The obtained lignin was characterized both using destructive technique such as nitrobenzene oxidation and nondestructive methods such as infra-red (IR), ultraviolet (UV), nuclear magnetic resonance (FTNMR) spectroscopy and gel permeation chromatography (GPC).

\section{EXPERIMENTAL}

\subsection{Material}

The empty fruit bunch (EFB) raw material used in this study was supplied by Sabutek (M) Sdn. Bhd., a local company specializing in recycling of EFB. The fibers were washed with water prior to pulping.

\subsection{Pulping conditions}

The EFB fiber was pulped in a $20 \mathrm{~L}$ stainless steel rotary digester unit with $25 \% \mathrm{NaOH}$ (cooking liquor) for 3 hours at a maximum cooking temperature of $170^{\circ} \mathrm{C}$, with a cooking liquor to $\mathrm{EFB}$ ratio of 10:1.

The $\mathrm{pH}$ of the obtained black liquor was 12.45 and its density $1.02 \mathrm{~g} / \mathrm{ml}$. The soda lignin was then precipitated from the concentrated black liquor by acidifying it to $\mathrm{pH} 2$ using various mineral acids at three levels of concentration i.e. $20 \%, 60 \%$ and concentrated. The acids used 
in this study were sulfuric acid, hydrochloric acid, phosphoric acid and nitric acid. The precipitated lignin was then filtered and washed with water that was adjusted to $\mathrm{pH} 2$ using the corresponding acid used in the earlier step. The soda lignin was then dried in a vacuum oven at $55^{\circ} \mathrm{C}$ for 24 hours prior to further analysis.

\subsection{Analysis of lignin}

Nitrobenzene oxidation was carried out by adding $50 \mathrm{mg}$ dry soda lignin into a mixture of $7 \mathrm{ml}$ of $2 \mathrm{M} \mathrm{NaOH}$ and $4 \mathrm{ml}$ of nitrobenzene in a $15 \mathrm{ml}$ steel autoclave. The autoclave was sealed tightly with a screw cap fitted with Teflon gasket and heated to $165^{\circ} \mathrm{C}$ for 3 hours in a preheated thermostat oil bath. After the heating period, the autoclave was cooled with ice water. The mixture was then transferred to a liquid-liquid extractor for continuous extraction with chloroform $(5 \times 20 \mathrm{ml})$ to remove any nitrobenzene reduction product and excess of nitrobenzene. The oxidation mixture was acidified by concentrated $\mathrm{HCl}$ to $\mathrm{pH} 3-4$ and further extracted with chloroform $(5 \times 15 \mathrm{ml})$. The solvent from the second chloroform solution was removed by using rotary evaporator at $40^{\circ} \mathrm{C}$ under reduced pressure to obtain the nitrobenzene oxidation mixture. The mixture was then dissolved into dichloromethane and made it up to $10 \mathrm{ml}$. This mixture was used as a stock solution for further analysis of the oxidation mixture ${ }^{5}$.

High performance liquid chromatography (HPLC) was used to analyze the nitrobenzene oxidation mixture. $0.2 \mathrm{ml}$ of stock solution was pipetted into $25 \mathrm{ml}$ volumetric flask and made it up with acetonitrile-water $(1: 2 \mathrm{v} / \mathrm{v})$. The resulting sample solution was filtered through a Millipore membrane (pore size $0.45 \mu$ ) to remove high-molecular weight contaminant and the 3,4,5trimethoxybenzadehyde was used as an internal standard. About $20 \mu \mathrm{l}$ of the filtrate was injected into the HPLC system (Shimatzu) equipped with Hypersil bond $\mathrm{C}_{18}$ column (particle size $5 \mu$, $25 \mathrm{~mm} \times 4.6 \mathrm{~mm}$ i.d.) to determine qualitatively the oxidation products. A mixture of acetonitrilewater (1:8) containing of $1 \%$ acetic acid was used as an eluent with a flow rate of $2 \mathrm{ml} / \mathrm{min}$. The eluent was monitored with an UV (ultraviolet) detector at $280 \mathrm{~nm}^{5}$.

The IR spectra were recorded on Perkin-Elmer 2000 spectrophotometer for each sample. The $\mathrm{KBr}$ pellets were prepared containing $1 \%$ fine ground sample. For the UV spectra, a Hitachi spectrophotometer model was used to obtain the results. Prior to the analysis, the samples (5 mg) were dissolved into $10 \mathrm{ml} 90 \%(\mathrm{v} / \mathrm{v})$ dioxane-water (aliquot). $1 \mathrm{ml}$ of aliquot was further diluted into $25 \mathrm{ml}$ by using $50 \%$ (v/v) doxane-water. The sample was then measured its absorbance for the range of $210 \mathrm{~nm}$ to $350 \mathrm{~nm}^{10}$.

The molecular weight distribution of the lignin was determined using gel permeation chromatography (GPC) on a PLgel $5 \mu$ Mixed-D column. Monodisperse polystyrene was used as the standard. $100 \mu \mathrm{l}$ of the sample with the concentration of $1 \mathrm{mg} / \mathrm{ml}$ was injected into the GPC. The temperature and flow rate of the column was set at $40^{\circ} \mathrm{C}$ and $1 \mathrm{ml} / \mathrm{min}$ respectively.

The $\mathrm{C}^{13}$-FTNMR spectra were obtained from a Bruker Avance 300 operating in the FT mode at $300 \mathrm{MHz}$ under total proton decoupled conditions. The spectra were recorded at $40^{\circ} \mathrm{C}$ from $200 \mathrm{mg}$ lignin dissolved in $1 \mathrm{ml}$ DMSO- $\mathrm{d}_{6}$ after 3,000 scans. A $90^{\circ}$ pulse flipping angle, a 26.6 $\mu$ s pulse width and a $1.74 \mathrm{~s}$ acquisition time were employed. 


\section{RESULTS AND DISCUSSIONS}

The yields of soda lignin precipitated by different mineral acids at various concentrations (v/v) are shown in Table 1.

Table 1: The average yields of lignin were recorded based on g/100 $\mathrm{ml}$ black liquor used

\begin{tabular}{|c|c|c|c|c|}
\hline \multicolumn{5}{|c|}{ Average Yield of lignin in $\mathrm{g}$ per $100 \mathrm{ml}$ black liquor for 3 trials } \\
\hline Concentration $(v / v)$ & Sulfuric Acid & Hydrochloric Acid & Phosphoric Acid & Nitric Acid \\
\hline $100 \%$ & $1.42 \pm 0.02$ & $1.37 \pm 0.01$ & $1.47 \pm 0.02$ & $1.20 \pm 0.03$ \\
\hline $60 \%$ & $1.44 \pm 0.01$ & $1.35 \pm 0.02$ & $1.45 \pm 0.01$ & $1.22 \pm 0.02$ \\
\hline $20 \%$ & $1.48 \pm 0.01$ & $1.40 \pm 0.01$ & $1.51 \pm 0.02$ & $1.27 \pm 0.02$ \\
\hline
\end{tabular}

It can be seen that the percentage recovery of soda lignin is influenced by the pulping condition ${ }^{6}$, the precipitation $\mathrm{pH}$ value ${ }^{11}$ and the type mineral acid used. The yield of soda lignin precipitated from hydrochloric acid and nitric acid were in the range of 1.20-1.33 g for every $100 \mathrm{ml}$ black liquor used, which is relatively low as compared to sulfuric acid and phosphoric acid (1.42-1.50 $\mathrm{g} / 100 \mathrm{ml}$ black liquor), indicating that yield is dependent on the number of hydrogen ions in the acid. The phosphoric acid, which has three hydrogen ions, gave the highest yield, follow by sulfuric, hydrochloric and nitric acid respectively, hence the preferable acid for precipitating soda lignin is phosphoric. It is also interesting to note that at low acid concentration (20\% v/ v), the yield of lignin consistently gave the highest value irrespective the type of acid used, which is probably due to the localized acidification or non-uniform precipitation effect when high acid concentration was used ${ }^{5}$.

Nitrobenzene oxidation is one of the standard procedures for analyzing lignin by chemical degradation technique in order to gain information about the composition of the original polymer. The composition of three monomeric lignin unit, viz p-hydroxyphenyl (H), guaiacyl (V) and syringyl (S) which are capable to produce the corresponding degradation product of p-hydroxylbenzadehyde, vanillin and syringaldehyde were analyzed on the results shown in Table 2.

Syringaldehyde was found to be the predominant followed by vanillin as a second major degradation product. The total yield of the oxidation products is ranged from $17.3 \%$ to $27.2 \%$. The lower total yield of oxidation products for concentrated sulfuric acid and $60 \%$ nitric acid may be explained by a higher condensation degree of the lignin ${ }^{7}$ and may consist of some polysaccharide material such as xylose as shown in the $\mathrm{C}^{13}$ FT-NMR spectra. For soda EFB lignin, the ratio of $\mathrm{S}$ : V: $\mathrm{H}$ was 7-15:6-11:1 which falls in the same category as cereal straw or grass type lignin 6,7 .

Typical IR spectra of soda lignin precipitation from various mineral acids are shown in Figure 1. The strong and broad band at $3433 \mathrm{~cm}^{-1}$ is the characteristic of $\mathrm{OH}$ group or phenolic compound. The band at $1330 \mathrm{~cm}^{-1}$ is due to the bending of vibration in phenolic $\mathrm{OH}$ group, whereas the 
Table 2: Yield and molar ratio of degradation products of the soda lignin by nitrobenzene oxidation

\begin{tabular}{lrrrrrrrrrrrr}
\hline & Sulfuric acid & \multicolumn{2}{c}{ Hydrochloric acid } & Phosphoric acid & \multicolumn{2}{c}{ Nitric Acid } \\
\hline Acid Concentration (\% v/v) & 20 & 60 & 100 & 20 & 60 & 100 & 20 & 60 & 100 & 20 & 60 & 100 \\
Oxidation product (\% w/w & & & & & & & & & & & & \\
to the internal standard) & & & & & & & & & & & & \\
p-hydroxybenzadehyde $\left(\mathrm{H}_{1}\right)$ & 1.1 & 0.8 & 0.6 & 1.0 & 0.7 & 0.8 & 1.1 & 0.9 & 0.7 & 1.0 & 0.9 & 0.8 \\
Vanillin $\left(\mathrm{V}_{1}\right)$ & 9.6 & 8.6 & 6.2 & 9.9 & 7.9 & 9.0 & 10.2 & 9.3 & 8.3 & 7.9 & 5.5 & 5.7 \\
Syringaldehyde $\left(\mathrm{S}_{1}\right)$ & 10.9 & 10.5 & 7.2 & 11.2 & 9.8 & 10.7 & 11.0 & 12.0 & 10.9 & 9.4 & 6.9 & 7.0 \\
p-hydroxybenzoic acid $\left(\mathrm{H}_{2}\right)$ & 0.2 & 0.3 & 0.2 & 0.3 & 0.3 & 0.3 & 0.2 & 0.2 & 0.2 & 0.3 & 0.2 & 0.3 \\
Vanillic acid $\left(\mathrm{V}_{2}\right)$ & 1.0 & 1.0 & 0.5 & 0.8 & 0.9 & 1.1 & 0.8 & 0.9 & 1.2 & 1.0 & 1.0 & 1.1 \\
Syringic acid $\left(\mathrm{S}_{2}\right)$ & 2.3 & 2.4 & 2.6 & 3.0 & 2.7 & 2.7 & 3.9 & 3.7 & 3.0 & 3.9 & 2.9 & 3.1 \\
p-coumaric acid $(\mathrm{B})$ & $\mathrm{T}$ & $\mathrm{T}$ & $\mathrm{T}$ & $\mathrm{T}$ & $\mathrm{T}$ & $\mathrm{T}$ & $\mathrm{T}$ & $\mathrm{T}$ & $\mathrm{T}$ & $\mathrm{T}$ & $\mathrm{T}$ & $\mathrm{T}$ \\
\hline \multicolumn{1}{c}{$\mathrm{Total}$} & & & & & & & & & & & & \\
$\left(\mathrm{H}_{1}+\mathrm{V}_{1}+\mathrm{S}_{1}+\mathrm{H}_{2}+\mathrm{V}_{2}+\mathrm{S}_{2}+\mathrm{B}\right)$ & 25.1 & 23.6 & 17.3 & 26.2 & 22.3 & 24.6 & 27.2 & 27.0 & 24.3 & 23.5 & 17.4 & 18.0 \\
\hline Molar ratio: $\mathrm{S} / \mathrm{H}$ & 10.2 & 11.7 & 12.3 & 11.8 & 12.5 & 12.2 & 11.5 & 14.3 & 15.4 & 7.3 & 8.9 & 9.2 \\
$\quad \mathrm{~V} / \mathrm{H}$ & 8.2 & 8.7 & 8.4 & 8.9 & 8.8 & 9.2 & 8.5 & 9.3 & 10.6 & 6.8 & 5.9 & 6.2 \\
$\mathrm{H} / \mathrm{H}$ & 1.0 & 1.0 & 1.0 & 1.0 & 1.0 & 1.0 & 1.0 & 1.0 & 1.0 & 1.0 & 1.0 & 1.0 \\
\hline
\end{tabular}

$\mathrm{T}=$ Trace amount; $\mathrm{S}=\mathrm{S}_{1}+\mathrm{S}_{2} ; \mathrm{V}=\mathrm{V}_{1}+\mathrm{V}_{2} ; \mathrm{H}=\mathrm{H}_{1}+\mathrm{H}_{2}$

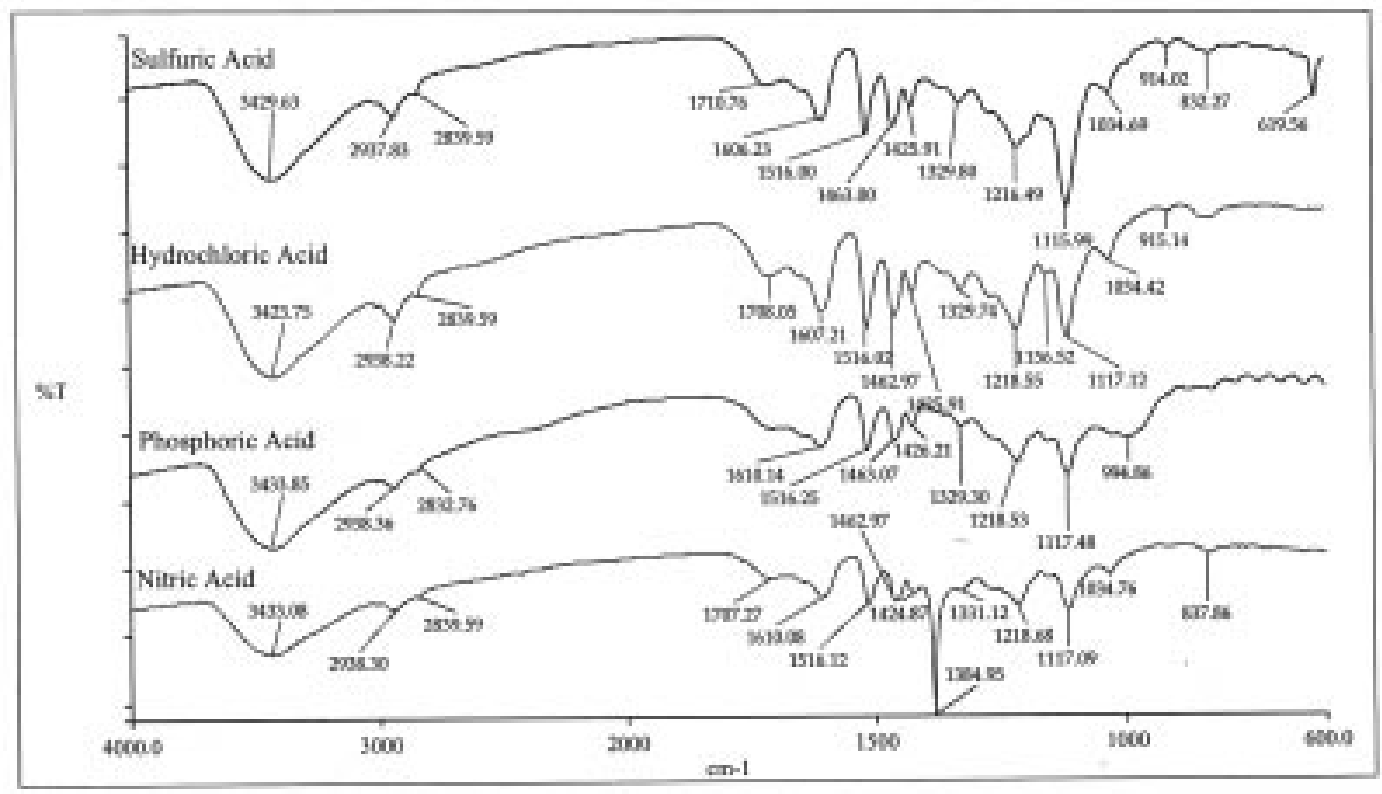

Figure 1 : Typical IR spectra of soda lignin precipitated from various mineral acids 
band at $1030 \mathrm{~cm}^{-1}$ is characteristic of a primary alcohol ${ }^{10}$. The clear shoulder at 2940-2930 $\mathrm{cm}^{-1}$ and the band at $1464 \mathrm{~cm}^{-1}$ are assigned to $\mathrm{CH}$ stretching of methyl or methylene group. Broad medium band at $1710 \mathrm{~cm}^{-1}$ is due to the conjugated carbonyl stretching. Moreover, two bands at $1516 \mathrm{~cm}^{-1}$ and $1610 \mathrm{~cm}^{-1}$ are characteristic of aromatic rings due to the aromatic skeletal vibrations and the band at $1117 \mathrm{~cm}^{-1}$ is due to the ether stretching. A band at 830$840 \mathrm{~cm}^{-1}$ indicates the C-H deformation and ring vibration. The strong and sharp band at 620 $\mathrm{cm}^{-1}$ that is only present in the spectrum of lignin precipitated from sulfuric acid is due to C-S stretching, whereas the spectrum of lignin precipitated from nitric acid showed a strong and sharp band at $1385 \mathrm{~cm}^{-1}$ which is characteristic of an $\mathrm{N}=\mathrm{O}$ stretching.

Bands at 1330, 1220 and $1120 \mathrm{~cm}^{-1}$ are corresponding to syringyl unit, whereas small bands at 1275,1153 and $1037 \mathrm{~cm}^{-1}$ are assigned to guaiaxyl unit of lignin molecules ${ }^{12}$. In general, the IR spectra of soda lignin isolated from different concentration levels were found to be the same suggesting that the general composition of lignin is not affected by the concentration and types of acids used.

The study of UV spectroscopy at 210-350 nm can be used to verify the purity of the precipitated lignin. From Figure 2, it can be seen that the maximum absorbance is at $235 \mathrm{~nm}$, which is assigned to the phenolate ion compound. The spectra also showed that intensity of absorbance is related to the level of lignin concentration, the higher the absorbance value the purer is the lignin compound. A lower absorbance could be due to the co-precipitated of non-lignin material such as polysaccharide degradation product such as ash and salts ${ }^{6}$.

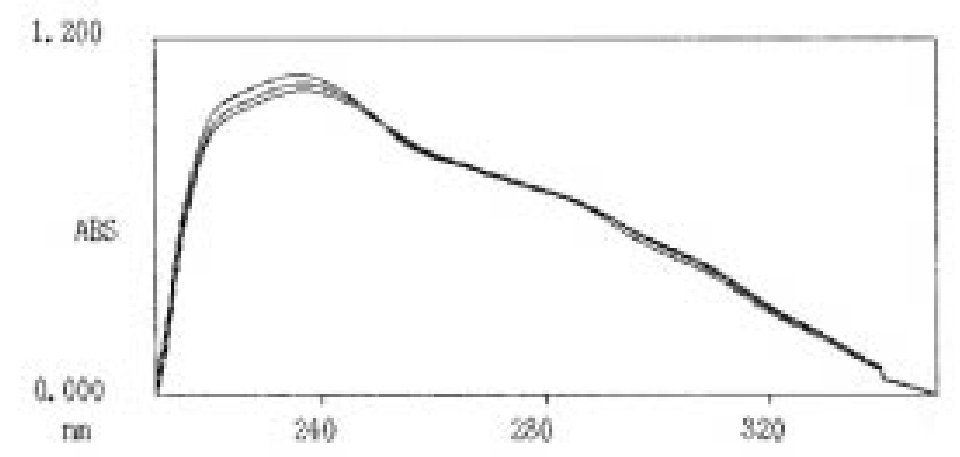

Figure 2 : Typical UV spectra of soda lignin precipitated from various concentrations of mineral acids

Table 3 : The absorbance and the maximum wavelength, $\lambda \max (n m)$ of lignin

\begin{tabular}{ccccc}
\hline \multicolumn{5}{c}{ Absorbance / $\lambda$ max (nm) of lignin } \\
Concentration (v/v) & Sulfuric Acid & Hydrochloric Acid & Phosphoric Acid & \multirow{2}{*}{ Nitric Acid } \\
\hline $100 \%$ & $1.085 / 235.8$ & $1.053 / 236.4$ & $1.105 / 235.5$ & $1.096 / 235.9$ \\
$60 \%$ & $1.030 / 236.5$ & $1.011 / 236.0$ & $1.037 / 236.2$ & $1.026 / 236.3$ \\
$20 \%$ & $1.052 / 236.3$ & $1.050 / 235.8$ & $1.063 / 236.4$ & $1.028 / 236.1$ \\
\hline
\end{tabular}


The absorbance values at the corresponding maximum wavelengths, $\mathrm{I}_{\max }$ were summarized in Table 3. It can be seen that the concentrated mineral acids regardless of their types gave the highest absorbance value followed by the $20 \% \mathrm{v} / \mathrm{v}$ and the $60 \% \mathrm{v} / \mathrm{v}$. The phosphoric acid exhibited the highest absorbance value (1.105) followed by nitric acid (1.096), sulfuric acid (1.085) and hydrochloric acid (1.053) at $\mathrm{I}_{\max }$ of $235 \mathrm{~nm}$.

From the GPC results, the weight-average $\left(\mathrm{M}_{\mathrm{w}}\right)$, number-average molecular weights $\left(\mathrm{M}_{\mathrm{n}}\right)$ and poly-dispersity $\left(\mathrm{M}_{\mathrm{w}} / \mathrm{M}_{\mathrm{n}}\right)$ values are calculated as shown in Table 4 . Lignin isolated by various mineral acids show no significant difference in their weight-average, which ranges from 2444 to 3279 . This range is slightly higher compared to alkaline lignin extracted from wheat straw and ash-anthraquinone lignin extracted from the $\mathrm{EFB}^{10,13}$. The results also indicate that the weightaverage molecular weights of lignin precipitated by concentrated mineral acid were consistently high due to the localized acidification and non-uniform precipitation effects ${ }^{5}$, with reasonably value of calculated $M_{w} / M_{n}$.

Table 4 : Weight-average and number-average molecular weights and poly-dispersity

\begin{tabular}{cccccccccccccc}
\hline & \multicolumn{1}{c}{ Sulfuric } & \multicolumn{1}{c}{ acid } & \multicolumn{1}{c}{ Hydrochloric acid } & \multicolumn{1}{c}{ Phosphoric acid } & \multicolumn{4}{c}{ Nitric Acid } \\
\hline Concentration (\%v/v) & 20 & 60 & 100 & 20 & 60 & 100 & 20 & 60 & 100 & 20 & 60 & 100 \\
$\mathrm{M}_{\mathrm{w}}$ & 2605 & 2930 & 3201 & 2872 & 2555 & 3274 & 2923 & 2444 & 3165 & 2974 & 3054 & 3279 \\
$\mathrm{M}_{\mathrm{n}}$ & 2076 & 1731 & 1694 & 1895 & 2065 & 2018 & 1953 & 2163 & 2143 & 2279 & 2531 & 2580 \\
$\mathrm{M}_{\mathrm{w}} / \mathrm{M}_{\mathrm{n}}$ & 1.23 & 1.69 & 1.89 & 1.52 & 1.24 & 1.62 & 1.60 & 1.13 & 1.48 & 1.31 & 1.21 & 1.27 \\
\hline
\end{tabular}

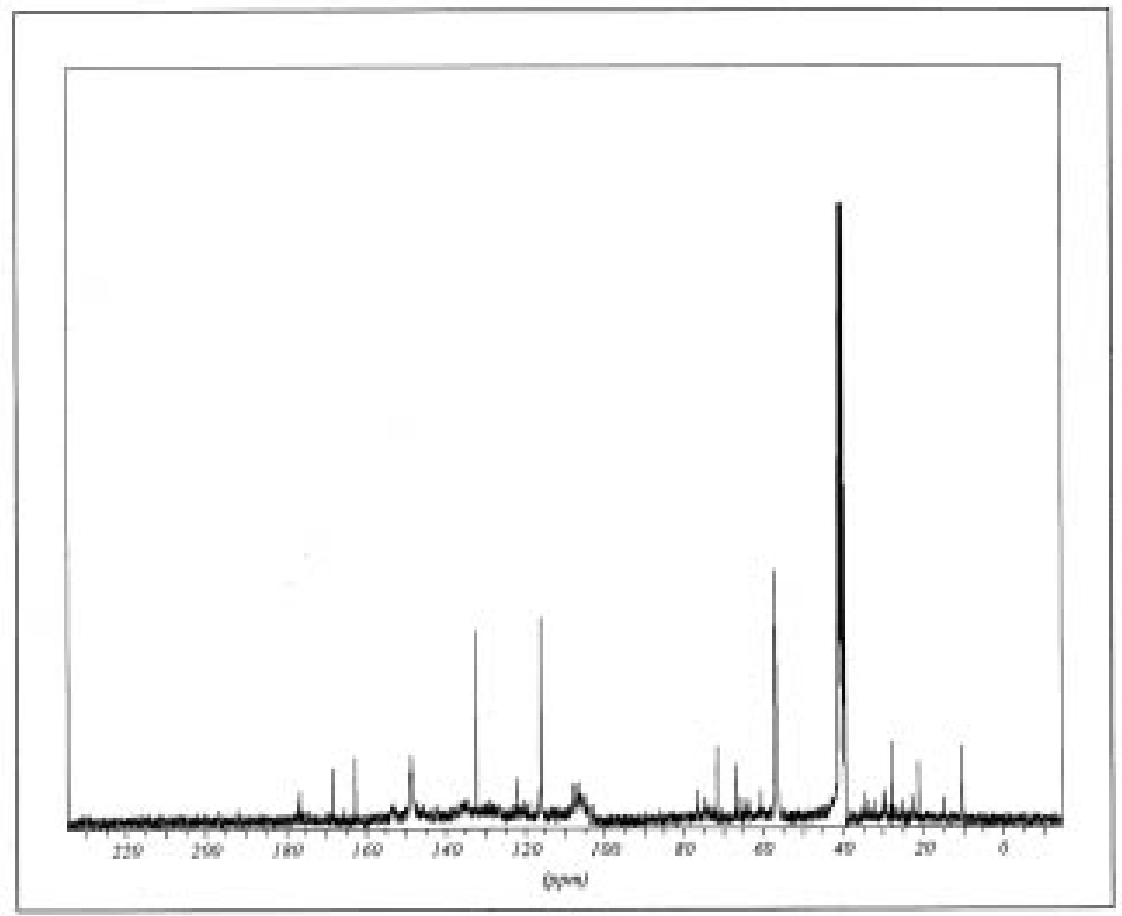

Figure 3 : $C^{13}$-NMR spectrum for lignin precipitated by $20 \% \mathrm{v} / \mathrm{v}$ sulfuric acid at $\mathrm{pH}_{2}$ 


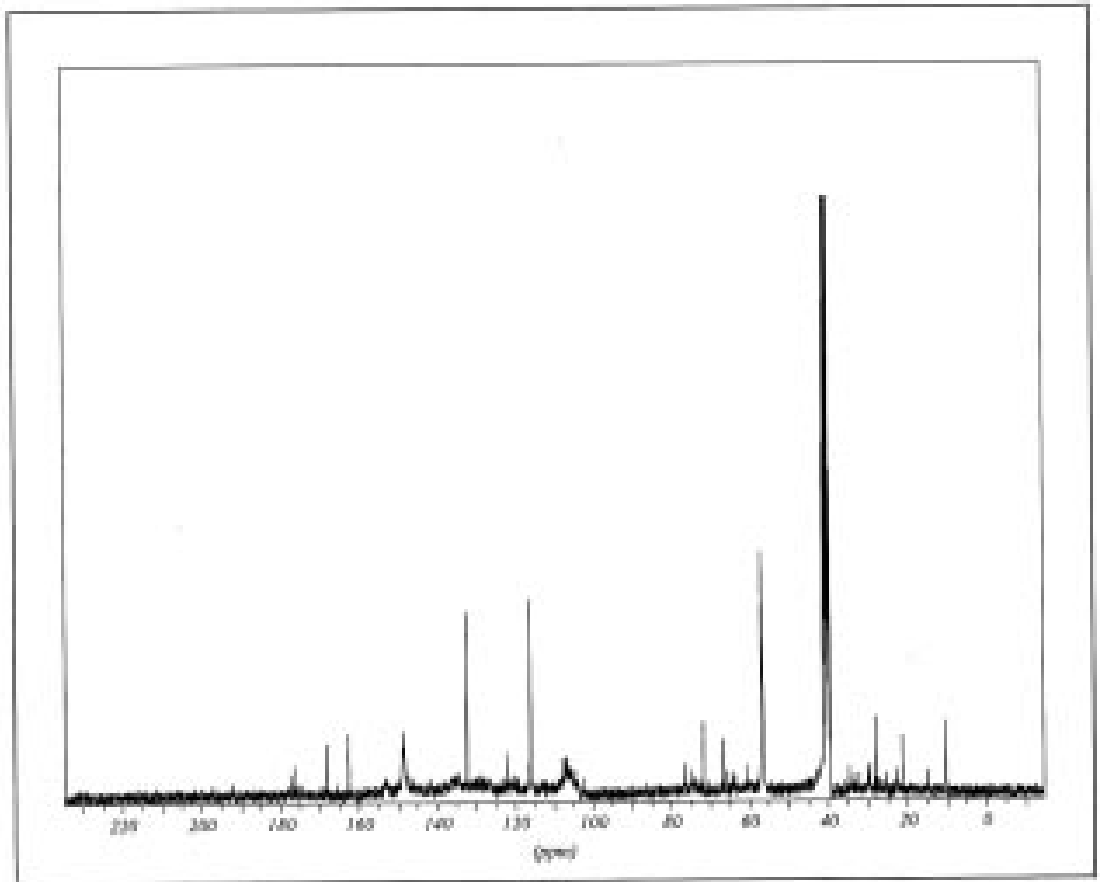

Figure $4: C^{13}$-NMR spectrum for lignin precipitated by $20 \% \mathrm{v} / \mathrm{v}$ hydrochloric acid at $\mathrm{pH}_{2}$

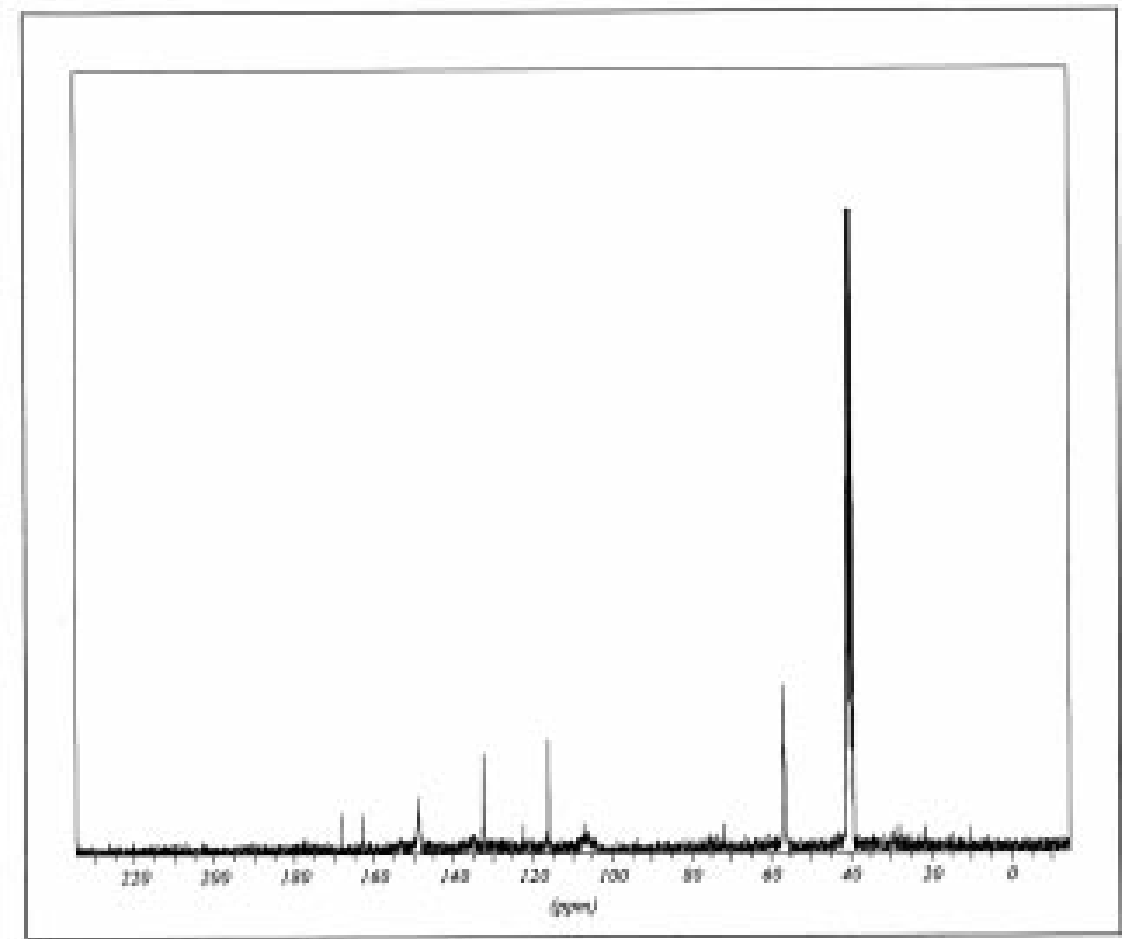

Figure $5: C^{13}$-NMR spectrum for lignin precipitated by $20 \% \mathrm{v} / \mathrm{v}$ phosphoric acid at $\mathrm{pH}_{2}$ 
AJSTD Vol. 21 Issue 1

Table 5: $\quad$ Carbon-13 chemical shift values ( $\delta p p m)$ and signal assignment of soda lignin isolated by various mineral acids

\begin{tabular}{|c|c|c|c|c|c|c|c|c|}
\hline \multicolumn{2}{|c|}{$\mathrm{H}_{2} \mathrm{SO}_{4}$} & \multicolumn{2}{|c|}{$\mathrm{HCl}$} & \multicolumn{2}{|c|}{$\mathrm{H}_{3} \mathrm{PO}_{4}$} & \multicolumn{2}{|c|}{$\mathrm{HNO}_{3}$} & \multirow[t]{2}{*}{ Assignment } \\
\hline$\delta$ ppm & Int. & $\delta$ ppm & Int. & $\delta$ ppm & Int. & $\delta$ ppm & Int. & \\
\hline & & & & & & 192.0 & $\mathrm{vw}$ & $\alpha$-CHO in benzadehyde \\
\hline 168.1 & $\mathrm{w}$ & 168.1 & $\mathrm{w}$ & 168.3 & vw & 168.1 & $\mathrm{w}$ & $\mathrm{CO}$ in acetates of phenols \\
\hline 162.5 & $\mathrm{~s}$ & 162.6 & s & 162.6 & vw & 162.5 & $\mathrm{~s}$ & C-4 in acetates of phenols \\
\hline 153.2 & vw & 153.2 & vw & & & 153.2 & $\mathrm{vw}$ & $\mathrm{C}-3 / \mathrm{C}-3^{\prime}$ in $\overline{\mathrm{e}} 5-5$ unit \\
\hline 149.0 & $\mathrm{w}$ & 149.0 & $\mathrm{w}$ & & & 149.0 & w & $\mathrm{C}-3,4$ in $\mathrm{Ge}$ \\
\hline \multirow[t]{2}{*}{148.7} & $\mathrm{w}$ & 148.7 & w & 148.8 & w & 148.7 & $\mathrm{~s}$ & \\
\hline & & 145.8 & $\mathrm{vw}$ & & & & & $\mathrm{C}-4$ in $\mathrm{G} \beta-o-4 \mathrm{n} \overline{\mathrm{e}}$ \\
\hline 135.0 & vw & 134.6 & vw & & & 135.0 & $\mathrm{vw}$ & $\mathrm{C}-1$ in $\mathrm{G}, \mathrm{S}$ with $\mathrm{C} 4 \mathrm{OR}$ \\
\hline 132.4 & vs & 132.3 & vs & 132.4 & $\mathrm{~s}$ & 132.4 & vs & $\mathrm{C}-1$ in $\mathrm{Gn} \overline{\mathrm{e}}$ \\
\hline \multirow[t]{2}{*}{130.1} & vw & & & & & 130.5 & $\mathrm{w}$ & $\mathrm{C}-1$ in $\mathrm{S}$ with $\alpha-\mathrm{COOH}$ \\
\hline & & 129.3 & vw & & & 129.4 & vw & $\mathrm{CH}$ : oleifinic and aromatic \\
\hline \multirow[t]{2}{*}{122.2} & w & 122.1 & $\mathrm{w}$ & 122.2 & vw & 122.2 & w & $\begin{array}{l}\mathrm{C}-6 \text { G }-\mathrm{CH} 2-; \mathrm{G}-\mathrm{CH} \\
\text { oleifinic carbons }\end{array}$ \\
\hline & & 119.1 & vw & & & 119.1 & vw & $\begin{array}{l}\text { C-6 G pinoresinol and } \\
\text { phenylcoumaran }\end{array}$ \\
\hline 116.0 & vs & 116.0 & vs & 116.0 & vw & 116.0 & vs & $\mathrm{C}-5$ in $\mathrm{G} \overline{\mathrm{e}}$ and $\mathrm{Gne} \overline{\mathrm{e}}$ \\
\hline 108.0 & $\mathrm{vW}$ & 108.0 & vw & & & 108.0 & $\mathrm{vW}$ & $\mathrm{C}-2$ vinyl ether \\
\hline 107.1 & vw & 107.1 & $\mathrm{vW}$ & 107.1 & vw & 107.1 & $\mathrm{~W}$ & $\begin{array}{l}\mathrm{C}-2 ; \mathrm{C}-6 \text { in } \mathrm{S} \text { with } \alpha-\mathrm{C}=\mathrm{O} \\
\text { or } \alpha-\mathrm{C}=\mathrm{C}\end{array}$ \\
\hline \multirow{4}{*}{106.6} & $\mathrm{vW}$ & 106.6 & $\mathrm{vW}$ & & & 106.6 & $\mathrm{~W}$ & \\
\hline & & 104.5 & vw & & & 104.5 & vw & $\mathrm{C}-2 ; \mathrm{C}-6$ in $\mathrm{S}$ in general \\
\hline & & & & & & 102.7 & vw & $\mathrm{C}-1$ in xylose internal unit \\
\hline & & & & & & 83.7 & $\mathrm{vw}$ & $\mathrm{C}-\beta$ in $\beta-o-4$ with $\alpha-\mathrm{CO}$ \\
\hline 76.2 & vw & 76.3 & vw & & & 76.4 & $\mathrm{vw}$ & \\
\hline 75.5 & $\mathrm{vW}$ & & & & & & & C-4 xylose \\
\hline \multirow{2}{*}{74.9} & vw & 74.9 & vw & & & 74.9 & $\mathrm{vw}$ & \\
\hline & & 73.6 & vw & & & 73.5 & vw & C-3 xylose \\
\hline \multirow[t]{2}{*}{71.6} & $\mathrm{~s}$ & 71.6 & $\mathrm{~s}$ & 71.7 & vw & 71.6 & $\mathrm{~s}$ & $\mathrm{C}-\alpha$ in $\beta-o-4$ \\
\hline & & & & & & 70.4 & vw & \\
\hline 66.6 & $\mathrm{w}$ & 66.6 & w & & & 66.6 & w & $C-\gamma$ \\
\hline 65.7 & vw & 65.7 & $\mathrm{vw}$ & & & 65.7 & $\mathrm{vw}$ & \\
\hline \multirow{2}{*}{65.5} & vw & 65.4 & vw & & & 65.5 & vw & \\
\hline & & 63.8 & vw & & & 63.8 & $\mathrm{vw}$ & $\mathrm{C}-\gamma$ in $\beta-o-4$ \\
\hline 60.4 & $\mathrm{vw}$ & 60.4 & $\mathrm{vw}$ & & & 60.4 & vw & C- $\gamma$ \\
\hline 56.9 & Vs & 56.9 & vs & 56.9 & $\mathrm{~s}$ & 56.8 & vs & $\mathrm{O}-\mathrm{CH} 3$ in $\mathrm{G}$ and $\mathrm{S}$ unit. \\
\hline \multirow[t]{2}{*}{56.8} & vs & 56.8 & vs & & & & & \\
\hline & & 56.5 & $\mathrm{~s}$ & & & & 56.5 & $\mathrm{~s}$ \\
\hline 34.5 & vw & 34.6 & vw & & & 34.5 & $\mathrm{w}$ & $-\mathrm{CH} 2-(\mathrm{G}-\mathrm{CH} 2-\mathrm{CH} 2-\mathrm{OH})$ \\
\hline \multirow[t]{3}{*}{33.6} & vw & 33.6 & vw & & & 33.6 & vw & $-\mathrm{CH} 2-$ \\
\hline & & 32.1 & vw & & & 32.1 & $\mathrm{vw}$ & \\
\hline & & 29.9 & $\mathrm{vW}$ & & & 29.9 & w & \\
\hline \multirow[t]{2}{*}{29.7} & vw & & & & & 29.7 & $\mathrm{~s}$ & \\
\hline & & & & & & 29.5 & $\mathrm{vw}$ & \\
\hline 29.4 & vw & 29.4 & vw & 29.4 & vw & 29.4 & w & \\
\hline 28.4 & vw & & & & & & & \\
\hline \multirow[t]{5}{*}{27.9} & $\mathrm{~s}$ & 27.9 & $\mathrm{~s}$ & 27.9 & vw & 27.9 & $\mathrm{~s}$ & \\
\hline & & & & & & 27.4 & vw & \\
\hline & & & & & & 27.1 & vw & \\
\hline & & 25.4 & vw & & & 25.3 & $\mathrm{w}$ & \\
\hline & & 22.9 & vw & & & 22.9 & $\mathrm{w}$ & \\
\hline \multirow[t]{2}{*}{21.3} & W & 21.3 & $\mathrm{w}$ & 21.3 & vw & 21.3 & $\mathrm{w}$ & \\
\hline & & 17.8 & $\mathrm{vw}$ & & & 14.8 & vw & - $\mathrm{CH} 3$ \\
\hline 10.3 & $\mathrm{~s}$ & 10.3 & $\mathrm{~s}$ & 10.3 & vw & 10.4 & $\mathrm{~s}$ & \\
\hline
\end{tabular}

$\mathrm{G}=$ Guaicyl, $\mathrm{S}=$ Syringyl, $\overline{\mathrm{e}}=$ etherified, $\mathrm{n} \overline{\mathrm{e}}=$ non-etherified vs=vary strong, s=strong, w=week, vw=vary week 


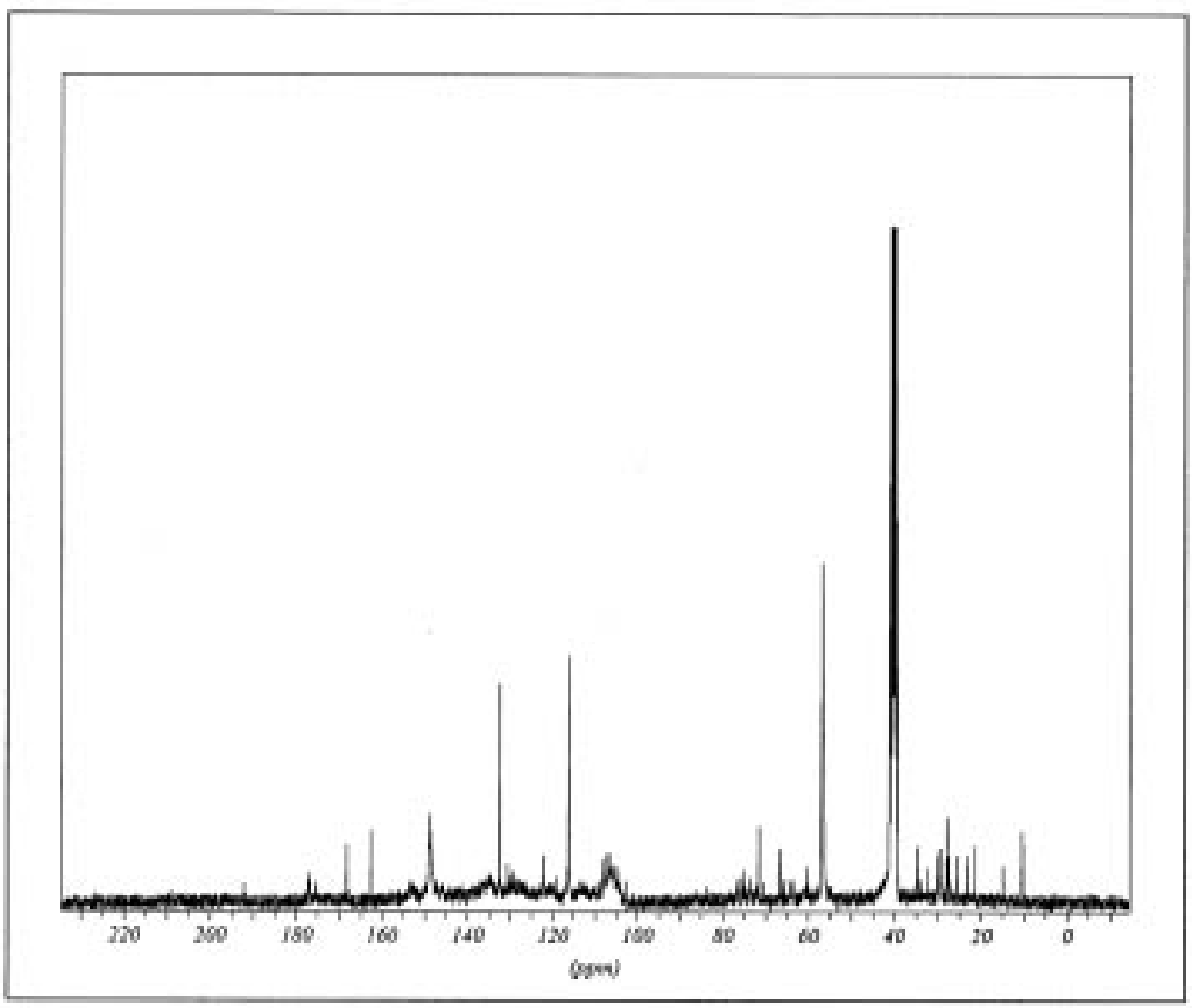

Figure $6: C^{13}-N M R$ spectrum for lignin precipitated by $20 \% \mathrm{v} / \mathrm{v}$ nitric acid at $\mathrm{pH}_{2}$

As evident from the spectra of $\mathrm{C}^{13}$-NMR (Figures 3-6), there is no significant difference in the structure of lignin precipitated by various mineral acids, probably because of the same-based components present in the lignins. The assignment of the peaks as given in Table 5 were made according to the literature data for lignin dissolved in DMSO- $\mathrm{d}_{6}{ }^{5,14-17}$. The incomplete dissolution of the sample may cause the signal/noise to be significantly high as exhibited in the spectra.

\section{ACKNOWLEDGEMENTS}

The authors would like to express their appreciations to Universiti Sains Malaysia and the Malaysian Ministry of Science, Technology and the Environment for the financial support of this project through a research grant. The authors also would like to thank Sabutek (M) Sdn. Bhd. for supplying the EFB long fiber for this study.

\section{REFERENCES}

1. Malaysian Palm Oil Board (MPOB)(2001), http://www.porim.gov.my

2. Akamatsu, I., Kobayashi, Y., Kamishima, H., Hassan, K., Mohd Yusoff, M.N., Husin, M. and Hassan, A.H. (1987), Cellulose Chemistry and Technology, vol. 21, pp. 191-197.

3. Khoo, K. C. and Lee, T.W. (1991), Appita, vol. 44, no. 6, pp. 385-388. 
4. Wan Rosli, W.D. and Law, K.N. (1988), Cellulose Chemistry and Technology, vol. 32, pp. 133-143.

5. Stephen, Y.L. and Carlton, W.D. (1992), Methods in Lignin Chemistry, $1^{\text {st }}$ Edition, Springer-Verlag Berlin Heidelberg, Germany.

6. Sun, R.C., Tomkinson, J. and James, B. (1999), Polymer Degradation and Stability, vol. 63, pp. 195-200.

7. Scalbert, A. and Monties, B. (1986), Holzforchung, vol. 40, p. 249.

8. Gellerstedt, G. and Lindfors, E.L. (1984), Holzforchung, vol. 38, p. 151.

9. Groot, B.D., Dam, J.E.G.V. and Riet, K.V. (1995), Holzforchung, vol. 49, p. 332.

10. Sun, R.C., Tomkinson, J. and Jones, G.L. (2000), Polymer Degradation and Stability, vol. 68, pp. 111-119.

11. Khairunisak, A.R., Oi, B.H., Sarani, Z., Sahrim, A. and Mohd Nor, M.Y. (2000), Effect of Kraft Pulping with Antharquinone and Methanol on Oil Palm Empty Fruit Bunches, $5^{\text {th }}$ National Seminar on Utilization of oil Palm tree and Other Palms, Kuala Lumpur, 9-11 May, 2000.

12. Rodrigues, J., Faix, O. and Pereria, H. (1998), Holzforchung, vol. 52, p. 46.

13. Sun, R.C., Lawther, J.M. and Banks, W.M. (1997), Holzforchung, vol. 51, p. 244.

14. Guittet, E., Lallemand, J.Y., Catherine, L. and Monties, B. (1984), Holzforchung, vol. 38, pp. 333-342.

15. Kringstad, K.P. and Roland, M. (1983), Holzforchung, vol. 37, pp. 237-244.

16. Akim, L.G., Fedulina, T.G. and Shevchenko, S.M. (1997), Holzforchung, vol. 51, pp. 419-427.

17. Nimz, H.H., Robert, D., Faix, O. and Nemr, M. (1981), Holzforchung, vol. 35, pp. 16-26. 